Counsellia: Jurnal Bimbingan dan Konseling, 9 (2), 2019|165-179

Copyright (C2019 Universitas PGRI Madiun

ISSN: 2088-3072 (Print) / 2477-5886 (Online)

Available online at: http://e-journal.unipma.ac.id/index.php/JBK

DOI: $10.25273 /$ counsellia.v9i2.5266

\title{
Metaanalisis karakter integritas siswa berbasis nilai Bundo Kanduang di Era Revolusi Industri 4.0
}

\author{
Yogi Damai Syaputra ${ }^{1}$, Nur Hidayah ${ }^{2}$, M. Ramli ${ }^{3}$, Alfaiz ${ }^{4}$ \\ ${ }^{1}$ Fakultas Ilmu Pendidikan, IAIN Batusangkar, Lima Kaum \\ yogi.ds@iainbatusangkar.ac.id \\ ${ }^{2}$ Fakultas Ilmu Pendidikan, Universitas Negeri Malang, Malang \\ nur.hidayah.fip@um.ac.id \\ ${ }^{3}$ Fakultas Ilmu Pendidikan, Universitas Negeri Malang, Malang \\ ramli.fip@um.ac.id \\ ${ }^{4}$ Program Studi Bimbingan dan Konseling, STKIP PGRI Sumatera Barat, Padang \\ alfaiz@stkip-pgri-sumbar.ac.id
}

\begin{abstract}
Abstrak
Permasalahan integritas masih menjadi pekerjaan rumah oleh pendidikan kita seperti masih banyak kecurangan akademik yang dilakukan oleh peserta didik, kurang sadar akan posisi, kewajiban sebagai peserta didik yang sedang proses belajar. Tujuan dari penelitian ini adalah melakukan kajian literatur menemukan aspek integritas seperti apa yang menjadi bagian dari belajar siswa di era revolusi industri 4.0, menganalisa nilai "Bundo Kanduang" untuk keterkaitannya dengan aspek integritas siswa, melakukan metanalisis nilai budaya "Bundo Kanduang" untuk menjawab pembentukan karakter integritas siswa. Riset ini dilakukan dengan studi literatur budaya melalui metanalisa kritis yang melahirkan sintesis baru. Hasil temuan menjelaskan bahwa aspek integritas menjadi dasar utama yang perlu ditanamkan bagi siswa dalam proses belajar, mengingat persaingan di era revolusi industri 4.0, nilai bundo kanduang memiliki esensi karakter kebenaran, kejujuran, konsisten, takwa, cerdas, mandiri, optimis, tanggung jawab, kreatif, terbuka dan berani, semua ini merupakan bagian diri yang berintegritas, dari hasil metaanalisis nilai tersebut, ditemukan 8 dari 12 nilai tersebut bisa menjadi bagian penting membentuk integritas siswa.
\end{abstract}

Keywords: Integritas, Karakter, Metaanalisis, Bundo Kanduang, Revolusi Industri 4.0

\begin{abstract}
The problematica of integrity has been a home work of our education in the last 5 years. It can bee seen there are lot of students still cheating in their academic process, and lack of learning awareness and less of responsibility in their school tasks. This is concerning of educator and counselor, integrity as consistensy, self awareness and responsibilities of person in activities. The objectives of this research is to analyse of literature about integrity in this industrial revolution 4.0. then analyse a culture value of bundo kanduang to answer a students integrity in learning. Then conduct a metanalysis about value of bundo kanduang and synthesize this value to shaping an integrity character of students as synthesize concepts. The result found that integrity aspects has been a primery foundation in era industrial revolution 4.0, a value of bundo kanduang has an essential in honestly,truth, concistence, taqwa, cleverness, autonomous, optimists, responsibility, creative, opennes, brave. In metaanalysis found that in 12 of bundo kanduang value there
\end{abstract}


are only 8 values that can bee synthesize as important part in shaping students integrity in learning.

Keywords: Integrity, Character, Metaanalysis, Bundo Kanduang, Industrial Revolution 4.0

\section{PENDAHULUAN}

Pembelajaran abad 21 peserta didik diharapkan mampu untuk berfikir kritis, berkomunikasi, berkolaborasi dan memiliki kreativitas yang tinggi. Pendidikan merupakan salah satu cara untuk mecarai keterampilan. Berdasarkan UU no 20 tahun 2003, yang bermakna bahwa pendidikan merupakan upaya sadar dan direncanakan untuk mewujudkan proses belajar dan pembelajaran agar peserta didik aktif dalam mengembangkan potensi diri dalam lingkup spiritual keagamaan, pengendalian diri, personaliti, intelektual, akhlak mulia, serta skil keterampilan yang diperlukan diri, masyarakat, bangsa, dan negara. Hal ini jelas bahwa muara dari pendidikan adalah membentuk sumber daya yang berkualitas. Serta juga membangun etika dalam berfikir, berperilaku, belajar hingga profesi (Alfaiz, 2018; Faiz, Dharmayanti, \& Nofrita, 2018)
Menjawab tantangan globalisasi saat ini, pemerintah memunculkan pendidikan karakter sebagai model atau wadah bagi pendidik dalam proses pembelajaran. Pendidikan karakter ini muncul karena adanya degradasi moral, etika dan budi pekerti, tuntutan skil yang diperlukan peserta didik adalah karakter, bacaan dasar dan Kompetensi 4C (Budhiman, 2017). Hal ini diperkuat dengan arahan khusus president untuk memperkuat pendidikan karakter yang dituangkan pada (Peraturan Presiden No 87, 2017) mengenai PPK, Proses tersebut juga tidak lepas dalam proses supervisi untuk meningkatkan kualitas pengajaran dan bimbingan (Yuzarion, Alfaiz, Kardo, \& Dianto, 2018)

Pendidikan karakter ini mengandung lima nilai-nilai utama karakter diantaranya (1) religusitas, nilai karakter yang tercermin dari perilaku keimanan pada tuhan yang maha esa, diwujudkan kepada proses kegiatan ibadah dan mengahargai 
perbedaan agama. Bagian nilai religius diantaranya cinta, damai, toleransi, teguh pendirian, percaya diri dll; (2) nasionalis, merupakan nilai karakter yang tergambar dalam wujud kesetiaan terhadap bangsa. Subnilai dari karakter nasionalis adalah menghargai budaya sendiri serta memelihara sumber alam bangsa, (3) mandiri, merupakan sikap tidak ketergantungan pada orang lain. Bagian nilai karakter ini adalah etos kerja, tangguh, semangat juang yang tinggi, profesional, dan kreatif serta keberanian, ini akan menjadi pembelajaran berkelanjutan; (4) gotong royong, nilai karakter yang mengapresiasi kerjasama dan tolong menolong dalam menyelesaikan problematika bersama. Subnilai gotong royong adalah musyawarah, kerjasama. (5) integritas, nilai yang mendasari perilaku untuk dapat dipertanggung jawabkan perkataannya, perbuatan, kesetian terhadap etika moral (integritas moral). Subnilai dari karakter integritas ini meliputi nilai jujur, cinta akan hal yang benar, loyal, integritas, berlaku adil, tanggung jawab, menjadi teladan, serta mengapresiasi harga diri individu (terutama penyandang disabilitas).

Nilai karakter yang menjadi sorotan utama terkait dengan nilainilai karakter integritas. Ditinjau dari subnilai yang terkandung dalam karakter tersebut, karakter ini belum banyak tertanam dalam diri peserta didik. Seperti contoh rasa jujur dan cinta pada kebenaran. Berdasarkan hasil wawancara penulis dengan beberapa siswa (Oktober-November 2017) terungkap bahwa diantara mereka masih susah bersikap jujur dalam pembelajaran, sulitnya untuk cinta akan kebenaran hal ini dibuktikan ketika ujian masih ada diantara siswa yang mencontek, hal ini karena mereka takut akan nilai gagal sehingga bermacam cara masih dilakukan termasuk cara-cara yang curang. Apabila ada siswa yang bersikap jujur kemudian siswa tersebut akan dikucilkan.

Berdasarkan pengumpulan data lewat wawancara dengan guru Bimbingan dan Konseling di Padang (10 November 2018) mengatakan bahwa sekarang yang menjadi permasalahan besar di sekolah adalah 
masalah karakter anak. Berita mengenai oknum guru yang dibully oleh siswa. Berdasarkan informasi yang didapatkan dari (Haryanto, 2018) menjelaskan peristiwa ini terjadi di SMK NU 03 Kaliwungu Kabupaten Kendal. Meskipun berdasarkan pengakuan kepala sekolah ini merupakan peristiwa guyonan, akan tetapi para siswa mencerminkan perilaku yang tidak santun dalam sikap dan perilaku peserta didik terhadap gurunya. Perilaku tersebut tentu saja disebabkan adanya proses pembelajaran yang tidak langsung dimodifikasi oleh siswa dalam pembelajaran di lingkungan yaitu pengalaman vikarius yang meningkatkan efikasi dirinya berperilaku (Alfaiz, 2015). Peristiwa ini tentu mendapatkan sorotan tajam dari lembaga pendidikan. Karena peristiwa ini memunculkan sikap karakter yang tidak bagus pada diri siswa terutama nilai-nilai integritas.

Berbagai macam upaya telah dilakukan oleh konselor untuk meningkatkan karakter siswa diantaranya: hasil penelitian Ferdiansyah yang menyatakan usaha yang bsia dilaksanakan oleh guru BK untuk meningkatkan karakter cerdas siswa untuk pemilihan karir melalui (1) pengayoman kepada siswa melalui berkolaborasi bersama guru, (2) pemberian layanan penyaluran dan penempatan, (3) layanan informasi dan orientasi, (4) layanan bimbingan dalam seting kelompok dengan tema karakter cerdas. Karakter spiritualitas juga menjadi fokus dalam membentuk integritas, hal ini disebabkan integritas merupakan komitmen kepribadian individu yang dibentuk melalui spiritual dan kognitif (Alfaiz, Hidayat Rafiola, Hariko, \& Zulfikar, 2017; Faiz et al., 2019).

Riset yang dilaksanakan oleh (Musafiri, Utaya, \& Astina, 2016) Menyimpulan nilai-nilai kearifan lokal suku using dapat mengurangi dampak globalisasi melalui penanaman nilai-nilai positif kepada remaja. Penelitian (Buchori, Ibrahim, \& Saman, 2016) menyatakan bahwa kegiatan outbond dalam latihan pendidikan karkater mampu meningkatkan kejujuran (integritas) mahasiswa. 
(Ghufron, 2010) menyatakan integrasi nilai karakter dapat dilaksanakan pada proses belajarmengajar. Melalui proses pembelajaran pendidik bisa menanamkan nilai-nilai integrasi sebagai pembentukan karakter siswa. Penelitian (Roshita, 2015) menyatakan bahwa sosiodrama melalui bimbingan seting kelompok efektif untuk mengembangkan perilaku sopan dan santun siswa. Penelitian (Faridah, 2015) menyatakan bahwa konseling kelompok melalui modeling bisa membentuk karakter menghormati pada peserta didik. Melalui treatmen yang diberikan berupa layanan konseling kelompok ternyata dapat meningkatkan karakter rasa hormat.

Berdasarkan beberapa hasil penelitian di atas, sudah ada beberapa kiat yang dilakukan oleh guru BK untuk meningkatkan nilainilai integritas siswa, akan tetapi penelitian yang dilakukan tidak menggunakan pendekatan yang berbasis nilai-nilai budaya. Padahal penanaman nilai-nilai integritas ini perlu dikembangkan dengan pendekatan- berbasis budaya.
Sumatera Barat merupakan provinsi di Indonesia yang beridentitas budaya tersendiri, dikenal dengan budaya Minangkabau. Populer dengan sistem kekerabatan matrilinial, menurut (Hadler, 2010) kekerabatan matrilinial adalah garis keturunan dan pewarisan dari ibu, ini menjadi komponen penting dalam budaya minangkabau. (Hans-Dieter Evers \& Ruediger Korff, 2000) menyatakan bahwa budaya Minangkabau merupakan penganut matrilinial terbesar di dunia. (Hakimy, 1997) mengatakan adat di minangkabau terbagi atas 4(empat) macam, diantaranya 1) adat istiadat; 2) nan saban adat; 3) nan teradat dan; 4) adat nan diadatkan. Keempat jenis adat ini menganut falsafah yang sama, "Adat Basandi Syara', Syara' Basandi Kitabullah". Artinya di Minangkabau segala ketentuan berlandaskan kepada Al-quran dan hadist. Falsafah hidup ini selalu menjadi pegangan bagi orang Minangkabau (Navis, 1984).

Seiring perkembangan zaman, tidak dapat dipungkiri nilai-nilai budaya telah banyak mengalami 
pergeseran, termasuk juga nilai-nilai budaya Minangkabau. Banyak faktor yang menyebabkan hal itu terjadi. Perkembangan informasi teknologi menjadi salah satu penyebab tergesernya nilai-nilai budaya di Minangkabau. Sebagai contoh berubahnya fungsi surau di Minangkabau, padahal surau merupakan sarana bagi anak untuk menuntut ilmu agama dalam mencapai proses kedewasaan. Penelitian (Fatimah, 2008), mengatakan bahwa telah tejadi pergerasan budaya minangkabau tertutama dalam peran mamak, hal ini dilihat dari perkembangan nilainilai zaman globalisasi. Berdasarkan hasil penelitian (Syahrizal \& Meiyenti, 2012) terungkap bahwa, pergeseran budaya Minangkabau terjadi pada (1) perubahan kelompok kekerabatan dan peran mamak, (2) perubahan posisi dan peran perempuan (3) perubahan istilah sistem kekerabatan, (4) perubahan pemilihan jodoh dan (5) perubahan penguasaan pengelolaan harta pusaka.

Salah satu kata pusaka yang populer di minangkabau dalam dunia pendidikan adalah "alam takambang jadi guru" artinya alam yang luas ini menjadi guru bagi peserta didik, menjadi tempat belajar mencari ilmu dari alam dan mencari makna apa yang terkandung di dalam alam. Hasil riset yang dilaksanakan (Zubaidah, 2014) tentang studi kata filsafat minangkabau dan kontibusinya terhadap konseling menghasilkan sebuah konsep tentang keterkaitan pepatah minangkabau dengan proses konseling. (Fitniwilis, 1998) juga melakukan penelitian terkait dengan nilai-nilai budaya bundo kanduang dan keterkaitan nilai-nilai ini dengan konseling.

Berdasarkan hal tersebut dapat dipahami bahwa nilai-nilai budaya bundo kanduang ini dapat dikembangkan menjadi suatu model khusus untuk perkembangan nilainilai karakter integritas siswa dalam konseling. Sehingga nilai budaya bundo kanduang di Minangkabau dapat diintegrasikan dalam pengembangan nilai-nilai karakter integritas siswa melalui pelayanan bimbingan dan konseling. Untuk memberikan pelayanan yang efektif kepada klien sangat dipentingkan 
wawasan multibudaya oleh konselor (Wibowo, 2015), sejalan dengan pandangan (Firman, 2018) menjelaskan bahwa untuk mewujudkan kehidupan efektif sehati-hari klien dapat menggunakan strategi konseling berbasis budaya. Dalam hal ini adala usaha untuk mengitegrasikan nilai budaya minangkabau dalam pelayanan konseling.

\section{METODE}

Jenis penelitian adalah kualitatif studi literatur budaya melalui pendekatan metaanalisa kritis yang melahirkan sintesis baru. (Creswell, 2014) metode dengan mengeksplorasi makna yang berasal dari variabel sosial atau kemanusiaan. Penelitian ini menggunakan kajian studi literatur. Menurut (Zed, 2008) studi literatur kontinuitas upaya yang berkaitan dengan pengumpulan dan analisa data kepustakaan, pencatatan, dan manajerial bahan riset. Studi ini merupakan aktivitas untuk pengembangan secara teoritis, maupun praktis, adapun tujuan penelitian dengan studi literatur adalah untuk mencari dasar pijakan dan fondasi untuk membangun teori.

\section{HASIL DAN PEMBAHASAN}

\section{Hasil Penelitian}

Berdasarkan proses kajian literatur nilai budaya dengan nilai karakter integritas yang diatur dalam peraturan pendidikan, serta proses menganalisa temuan lapangan dan teoritis untuk mengungkap keterkaitan nilai budaya dengan karakter dalam pendidikan berikut hasil kajian tersebut.

\section{Karakter Integritas Siswa}

Penguatan karakter merupakan usaha untuk mewujudkan peserta didik yang memiliki personaliti yang bagus, bagaimana menjadikan perseta didik yang pintar dan juga baik. Dua aspek ini harus seimbang untuk mewujudkan identitas yang baik (good identity).

Nilai-nilai

Karakter dikristalisasikan atau dikelompokan kepada lima nilai utama karakter. Kelima nilai utama ini harus melekat pada peserta didik. Adapun lima nilai utama itu adalah nasionalisme, religiusitas, mandiri, gotong royong dan integritas.

Hasil penelitian ini fokus untuk penguatan karakter integritas pada siswa. Nilai integritas yang akan dikembangkan melalui nila-nilai budaya bundo kanduang adalah (1) Nilai Kejujuran, (2) Nilai Keteladanan, (3) Nilai Kesantunan, (4) Nilai Cinta Pada Kebenaran.

\section{Pendidikan Karakter}

Hill (Chrisiana, 2005) mengatakan, "karakter menentukan 
pikiran pribadi seseorang dan tindakan seseorang dilakukan. Karakter yang baik adalah motivasi batin untuk melakukan apa yang benar, sesuai dengan standar perilaku tertinggi dalam setiap situasi”. Perilaku yang ditampilkan, dilukiskan atau digambarkan oleh seseorang akan menjadi sebuah gambaran karakter bagi individu itu sendiri.

Menurut (Elkind, D \& Sweet, 2004) pendidikan karakter merupakan sebagai bentuk pendidikan yang didesain untuk mengarahkan dan membantu siswa dalam mengembangkan potensi dan membentuk karakternya, etika dan melayani masyarakat sekitarnya, memulihkan iklim sekolah serta meningkatkan prestasi belajar siswa. Program ini melingkupi kepercayaan termasuk, integritas, rasa hormat, toleransi, sikap sopan santun, tanggung jawab, termasuk kerja keras, kemandirian, akuntabilitas, ketekunan, dan pengendalian diri dan keadilan. Senada dengan itu (Williams, M \& Schaps, 1999) menjelaskan pendidikan karakter adalah beraneka upaya yang dilaksanakan oleh personil sekolah, bahkan dilaksanakan berkerjasama dengan orang tua juga dengan masyarakat untuk membantu anakanak dan remaja agar memiliki kepedulian, berpendirian dan bertanggung jawab. Jadi pendidikan karakter merupakan usaha yang dilakukan untuk membentuk peserta didik agar memiliki identitas diri yang baik, yang memiliki nilai-nilai kejujuran, toleransi, sopan santun, kesetian, kemandirian tanggungjawab.

Tahun 2016 pemerintah mengembangkan pendidikan karakter menjadi program penguatan pendidikan karakter (PPK). Hal ini tentunya mengembangkan pendidikan karakter yang digagas sebelumnya. Menurut (Budhiman, 2017) dari Kemeneterian Pendidikan dan Kebudayaan menjelaskan bahwa program pendidikan untuk penguatan karakter ini adalah Usaha pengajaran yang difokuskan dalam lembaga pendidikan yaitu sekolah untuk membentuk karakter peserta didik yang mahir dalam berfikir, merasakan, spiritual hingga kemampuan psikomotor (fisik) dengan bersinergi bersama antara lembaga sekolah, masyarakat dan keluarga.

\section{Pembahasan}

Untuk menemukan sintesis dari proses kajian ini, maka perlu kajian analisis literatur lebih detail, sebagai berikut

\section{Metaanalisis Nilai Integritas Berbasis Nilai Budaya Minangkabau}

Budaya Minangkabau merupakan budaya yang manganut sistem matrilinial. Sistem menurut garis keturunan Ibu. Hal ini menandakan betapa pentingnya posisi perempuan di Minangkabau. 
(Hakimy, 1997) ada tiga kategori perempuan di Minangkabau diantaranya: pertama parampuan (perempuan) berasal dari kata empu yang artinya yang pertama dan utama; kedua parampuan simarewan istilah yang mengacu kepada perempuan yang kurang mempunyai pendirian dan kurang bijaksana; dan parampuan mambang tali awan adalah perempuan yang tinggi hati, yang sering tidak punya rasa hormat, tenggang rasa, selalu ingin dihormati kedudukannya. Kategori perempuan (parempuan) dijadikan panutan di Minangkabau yang disebut bundo kanduang.

Sejatinya bundo kanduang menjadi gambaran sosok perempuan minang yang anggun, tangguh dan bijaksana. Karakter seorang bundo kanduang tergambar dalam pepatah yakni,

\section{Bundo kanduang \\ limpapeh rumah nan gadang, umbuih paruih pegangan kunci, umbun paruih alun bunian, pusek kumpulan tali, sumarak dalam kampuang, hiasan dalam nagari, nan gadang basah batuah, kok hiduik tampek banasa, kok mati tampek baniaik, ka undang-undang ka Madinah, ka payuang panji ka sarugo. (Hakimy, 1997).}

Pepatah ini mengandung makna bahwa seorang perempuan berperan sebagai penyanggah rumah tangga, pemegang kunci harta kekayaan, sumber segala titah, kumpulan segala sistem, membuat kampung menjadi meriah, menjadi perhiasan di dalam kampung, tempat memintak nasehat dan menjadi tauladan bagi perempuan minang.

Nilai-nilai budaya bundo kanduang banyak yang mengandung unsur pendidikan. Nilai-nilai ini dijadikan sebagai pedoman dalam bersikap, berpikir dan bertindak bagi masyarakat minangkabau. Hasil penelitian (Fitniwilis, 1998) mengatakan terdapat 12 nilai-nilai budaya bundo kanduang di minangkabau yang mengandung unsur-usnur konseling diantaranya: (1) Nilai Keberanian, (2) Kebenaran, (3) Kejujuran, (4) Kekonsistenan, (5) Keoptimisan, (6) Ketakwaan, (7) Keterbukaan, (8) Kecerdasan, (9) Kekreatifan, (10) Penyesuaian, (11) Kemandirian dan, (12) Nilai Tanggungjawab. Nilai yang terkandung dalam budaya bundo kanduang ini selaras dengan nilainilai pendidikan karakter. Nilai karakter yang akan dibahas melalui tulisan ini adalah karakter integritas.

\section{Nilai Kejujuran}

Nilai kejujuran merupakan hal yang penting bagi soerang bundo kanduang. Perkataan bundo kanduang akan selalu didengar oleh kaumnya, apabila dia dusta maka kepercayaan kaumnya akan hilang, ini menandakan jujur merupakan sifat yang harus dimiliki oleh soerang bundo kanduang. Hal ini 
tergambar dalam pepatah "nak luruih bontangkan tali, nak jan manyimpang suok jo kida, luruih manuruik barih adat, adat basandi syara', syara' basandi kitabullah". Pepatah ini mengandung makna, bahwa seorang bundo kandung harus memiliki sifat jujur. Karena segala perilaku yang ditampilkan berlandasakan kepada adat yang mengacu atau berlandaskan kepada agama. (Fitniwilis, 1998) mengungkapkan sifat yang mesti dimiliki oleh seorang bundo kanduang adalah (1) berani pada kebenaran, (2) jujur dalam tindakan, (3) cerdik dalam kehidupan, (4) pemurah dan pemahal, (5) penyabar dan ridho.

Nilai kejujuran ini menjadi prioritas bagi seorang individu dalam bersikap dan bergaul dengan masyakarat. Ini tentu menjadi karakter penting bagi seorang siswa. Siswa yang baik adalah siswa yang memiliki sifat jujur dalam dirinya, takut untuk berbohong. Pada hari ini nilai-nilai jujur pada siswa sudah mulai terkikir dari dalam dirinya, hal ini terlihat dari sikap dalam beprilaku ketika ujian dan ketika belajar. Permasalahan ini akan bisa diatasi apabila setiap pendidik mengimplementasikan nilai-nilai budaya dalam proses pembelajaran. Menerapkan nilai-nilai budaya merupakan salah satu aspek yang bisa mengurangi nilai-nilai radikal siswa.

\section{Nilai Kesantunan}

Etika dan akhalak yang baik adalah cerminan perilaku bundo kanduang. bisa melakukan penempatan diri dimanapun sesuai kondisi. Berdasarkan KBBI (2008), "budi pekerti" adalah sistem batin sebagai panduan pikiran dan perasaan untuk mempertimbangkan "baik dan buruk". Seseorang yang baik budi pekerti dan tingkah lakunya, sabar serta berpenampilan tenang, dan santun (Abdurahman, 2012). Wujud dari sopan santun dalam minangkabau senantiasa ditandai dengan tahu "kato nan ampek, (kata yang empat)". Kato mandaki adalah etika individu dalam bersikap dan berkata kepada orang tua dari kita, seperti anak kepada bapak ibunya, murid pada guru. Kato manurun merupakan etika seorang yang tua dalam berinteraksi kepada orang yang lebih muda usianya, contoh kakak kepada adiknya, guru kepada muridnya. Kato mandata artinya cara bersikap dan perilaku kepada orang yang sama besar, seperti berbicara kepada teman sama besar. Kato malereng merupakan tatacara berbahasa yang digunakan dalam pergaulan "segan menyegan (saling menghargai)", seperti adik ipar kepada kakak iparnya.

Nilai sopan santun inilah yang harus dikembangan untuk menjawab tantangan zaman abad 21. Nilai sopan santun hari ini sudah jauh dari apa yang diharapkan, semakin berkembang zaman sopan santun 
dalam interaksi harus semakin terbangun sehingga membentuk perilaku positif saling mengapresiasi dan menerima satu dengan yang lain (Syaputra \& Monalisa, 2018). Kejadian kejadian yang dijumpai disekolah menggambarkan bagaimana seorang murid yang tidak lagi menghargai dan menghormati gurunya. Cara berbicara murid yang tidak menunjukan sikap seorang pelajar. Melalui penguatan pendidikan karakter bermuatan budaya ini tentu akan dapat meningkatkan etika dan sopan santun seorang siswa. Peran yang paling penting adalah menanamkan atau mensinergikan nilai budaya dalam penguatan karakter.

\section{Nilai Cinta Pada Kebenaran}

Nilai cinta kebenaran dalam nilai bundo kanduang ini tergambar dalam pepatah "manampuah jalan nan pasa (mengikuti cara yang benar)". Menurut (Devi, 2014), jalan nan pasa bermakna jalan untuk sampai kepada tujuan. Seorang bundo kanduang sangat menjunjung tinggi nilai kebenaran. Ini tergambar dalam pepatah "Nan gadang basa batuah" ka undang undang ka Madinah, ka payuang panji ka Saruga". Ini mengandung makna bahwa bundo kandunag adalah sosok yang tegur pendirian pada kebenaran. Bundo kanduang sangat cinta akan kebeneran, "kok salah katokan salah, kok bana katokan bana" ini artinya jika salah harus berani mengatakan salah, jika benar harus berani mengatakan benar inilah wujud cinta kebenaran dari nilai-nilai bundo kanduang.

Hari ini cinta akan kebenaran ini benar-benar sudah terkikis dari dalam diri masyarakat individu. Begitu banyaknya kasus korupsi yang terjadi, ini salah satu wujud tidak cinta akan kebenaran. Ini menjadi peran penting bagi dunia pendidikan untuk menanamkan nilai cinta kebenaran kepada siswa. Karena dengan cinta akan kebenaran ini akan membuat hidup kita menjadi tentran dan damai.

\section{Nilai Keteladanan}

Nilai keteladanan bundo kanduang tergambar dari pepatah sebagai berikut. "masaklah buah kacang padi, dibaok nak rang ka tangah pasa, padi nan masak batangkai-batangkai, bundo kanduang tuladan budi, paham usah namuah tajua, budi nan indak amuah tagadai". Ungkapan ini menjelaskan bahwa pribadi bundo kanduang merupakan teladan budi bagi masyarakatnya. Menurut (Devi, 2014) seorang Bundo Kanduang adalah tempat menauladani, "kasuri tuladan kain, kacupak tuladan batuang, satitiak namuah jadi lawuik, sakapa buliah jadi gunuang". Artinya etika dan akhlak merupakan tujuan utama seorang ibu dalam mengarahkan dan mendidik anaknya. Sosok ibu menjadi cerminan bagi anaknya seperti bunyi pepatah berikut: "Kalau karuah aie di hulu, sampai ka muaro karuahjuo, kalau 
kuriak induaknyo, rintiak anaknyo, tuturan atok jatuah ka palimbahan".

Kehadiran bundo kanduang merupakan sosok ideal seorang perempuan minangkabau. Perilaku yang digambarkan oleh bundo kanduang adalah cerminan dari perilaku perempuan-perempuan minang yang sebenarnya. Nilai keteladanan ini juga menjadi penting untuk diterapkan dalam proses pendidikan. Pendidik harus menjadi contoh kepribadian dan perilaku yang bagus bagi siswanya, karena siswa akan meniru segala tindak tanduk perilaku yang dimunculkan oleh gurunya.

Konseling berbasis budaya ini sangat diperlukan dalam layanan konseling. Individu yang berasal dari latar belakang budaya yang berbeda akan berbeda pula cara pandang dan sikapnya dalam berperilaku. Konseling multicultural menjadi aspek penting dalam penyelesaian masalah kien. Pendekatan ini menjadi topic hangat yang bicarakan dikalangan konselor, karena memadukan konseling dengan dimensi budaya yang terikat pada diri klien (Lee, 2006; Vacc, DeVaney, \& Brendel, 2003; Wing Sue, D., \& Sue, 2008) Oleh karena itu, nilai-nilai yang terkandung dalam bundo kanduang dapat dijadikan sebagai referensi untuk menambah wawasan konseling multikultural bagi konselor sekolah.

\section{SIMPULAN}

Melahirkan peserta didik yang tangguh dan kuat serta berkepribadian yang baik adalah tujuan utama dalam pendidikan karakter. Tujuan ini akan mengahasilkan generasi emas pada tahun 2045. Nilai-nilai integritas pada siswa perlu untuk dikembangkan dan ditingkatkan, nilai-nilai integritas ini langsung berhadapan dengan kehidupan yang jalani. Upaya yang dapat dilakukan untuk meningkatkan nilai ini adalah melalui proses kegiatan bimbingan dan konseling berbasis value dari budaya. Bundo kanduang dapat dikombinasikan dengan keilmuan bimbingan dan konseling, diantara nilai kejujuran, sopan, nilai cinta kebenaran dan keteladanan. Nilainilai ini dapat membantu program pemerintah dalam penguatan pendidikan karakter berbasis nilainilai budaya.

\section{DAFTAR PUSTAKA}

Abdurahman. (2012). Nilai-Nilai Budaya Dalam Kaba Minangkabau. Padang: UNP Press.

Alfaiz. (2015). KONSEP DIRI DAN EFIKASI DIRI SEBAGAI POIN MENDASAR DALAM AKTIVITAS SOSIAL ( SEBUAH ANALISIS PSIKOLOGIS : TEORI KOGNITIF SOSIAL ) Abstrak PENDAHULUAN Pemerintah dengan aturan undang- undang sistem pendidikan nasional nomor 20 tahun 2003 pasal 1 
butir 1 “P. Jurnal Pelangi, 7(2), 200-211.

Alfaiz, A. (2018). Guidance and Counseling Profession: A Philosophy and Professional Challenges In the Future. COUNS-EDU: The International Journal of Counseling and Education, 3(2), 41-47. https://doi.org/10.23916/002018 0313420

Alfaiz, A., Hidayat Rafiola, R., Hariko, R., \& Zulfikar, Z. (2017). Condition and Shaping of Student Personality in Educational Process Through Transpersonal Psychology Perspective. 128(Icet), 1-4. https://doi.org/10.2991/icet17.2017.1

Buchori, S., Ibrahim, M., \& Saman, A. (2016). Pengaruh character education training melalui outbound training untuk peningkatan kejujuran dan integritas. Jurnal Psikologi Pendidikan Dan Konseling: Jurnal Kajian Psikologi Pendidikan Dan Bimbingan Konseling, $\quad 2(1), \quad 12$. https://doi.org/10.26858/jpkk.v2 i1.2089

Budhiman, A. (2017). Penguatan Pendidikan Karakter: Arahan Khusus Presiden Gerakan Nasional Revolusi Mental [Strengthening Character Education: Special Presidential Directive National Mental Revolution Movement]. Retrieved from cerdasberkarakter.kemdikbud.g o.id/content/download/44

Chrisiana, W. (2005). Upaya Penerapan Pendidikan Karakter
Bagi Mahasiswa (Studi Kasus di Jurusan Teknik Industri Uk Perta). Jurusan Teknik Industri, Fakultas Teknologi Industri, Universitas Kristen Petra, 7(1), 82-90.

Creswell, J. W. (2014). Research Qualitative, Quantitative, and Mixed Methods Approaches Design Fourth Edition. In Sage Publications (Vol. 66). USA.

Devi, S. (2014). Kedudukan dan Peran Bundo Kanduang. In Kemendikbud (Vol. 2). Retrieved from http://repositori.kemdikbud.go.i d/10797/1/Kedudukan dan peran bundo kanduang.pdf

Elkind, D \& Sweet, F. (2004). You are a Character Education. Toda's School Peter Li Education Group.

Faiz, A., Dharmayanti, A., \& Nofrita, N. (2018). Etika Bimbingan dan Konseling dalam Pendekatan Filsafat Ilmu. Indonesian Journal of Educational Counseling, 2(1), 1-12. https://doi.org/10.30653/001.20 1821.26

Faiz, A., Yandri, H., Kadafi, A., Mulyani, R. R., Nofrita, N., \& Juliawati, D. (2019). Pendekatan Tazkiyatun An-Nafs untuk membantu mengurangi emosi negatif klien. Counsellia: Jurnal Bimbingan Dan Konseling, $\quad 9(1), \quad 65$. https://doi.org/10.25273/counsel lia.v9i1.4300

Faridah, D. N. (2015). Efektivitas Teknik Modeling Melalui Konseling Kelompok Untuk Meningkatkan Karakter Rasa Hormat Peserta Didik ( Quasi Eksperimen Terhadap Siswa 
Kelas $\quad X \quad d i \quad S M K$ Muhammadiyah 2 Bandung Tahun Pelajaran 2014 / 2015 ). 5(1), 45-66.

Fatimah, S. (2008). Mencermati Perubahan Sosial Masyarakat Minangkabau Melalui Novel Tamu Karya Wisran Hadi. Humaniora, 20(3), 278-285. https://doi.org/10.22146/jh.v20i 3.944

Firman. (2018). KEKUATAN KOMPETENSI BUDAYA KONSELOR DALAM LAYANAN KONSELING. (October).

Fitniwilis. (1998). Nilai-nilai Budaya Bundo Kanduang dan Kontribusinya dalam Pelayanan Konseling. Universitas Negeri Malang.

Ghufron, A. (2010). Integrasi NilaiNilai Karakter Bangsa Pada Kegiatan Pembelajaran. Cakrawala Pendidikan, 1(3), 13-24.

https://doi.org/10.21831/cp.v1i3 .230

Hadler, J. (2010). Sengketa Tiada Putus: Matriakat, Reformisme Islam, dan Kolonialisme di Minangkabau. In Freedom Institute.

Hakimy, I. (1997). Peganggan Penguhu, Bundo Kanduang, dan Pidato Alua Pasambahan Adat Di Minangkabau. Bandung: Remadja Rosda Karya.

Hans-Dieter Evers \& Ruediger Korff. (2000).

Southeast_Asian_Urbanism_Th e_Meaning_and_Power_of_. Malaysia: Researchgate.

Haryanto, I. (2018, November). Detiknews. DetikNews.
Lee, C. C. [Ed]. (2006). Multicultural issues in counseling: New approaches to diversity. Multicultural Issues in Counseling: New Approaches to Diversity., 315. https://doi.org/10.1017/CBO978 1107415324.004

Musafiri, M. R. Al, Utaya, S., \& Astina, I. K. (2016). Integrasi Nilai-Nilai Kearifan Lokal Suku Using. 258-270.

Navis, A. . (1984). Alam Takambang Jadi Guru, Adat dan Kebudayaan Minangkabau. Jakarta: Gratifi Pers.

Presiden, P. (2017). Lembaran Negara Republik Indonesia Tentang Penguatan Pendidikan Karakter. (223).

Roshita, I. (2015). Upaya Meningkatkan Perilaku Sopan Santun Melalui Layanan Bimbingan Kelompok Dengan Teknik Sosiodrama. 1(2), 29 35.

Syahrizal, \& Meiyenti, S. (2012). The Contemporary System of Minangkabau Kinship: a Study of Changes and the Continuity of the Minangkabau Matrilineal Kinship System. The 4th International Conference of Indonesian Studies: Unity. Diversity, and Future, 913--927. Retrieved from https://icssis.files.wordpress.co m/2012/05/09102012-71.pdf

Syaputra, Y. D., \& Monalisa, M. (2018). Kontribusi Kecerdasan Emosional Terhadap Interaksi Sosial Mahasiwa. Biblio Couns: Jurnal Kajian Konseling Dan Pendidikan, 1(1), 29-34. https://doi.org/10.30596/biblioc ouns.v1i1.1942 
Vacc, N. A., DeVaney, S. B., \& Brendel, J. M. (2003). Counseling multicultural and diverse populations: Strategies for practitioners, fourth edition. In Counseling Multicultural and Diverse Populations: Strategies for Practitioners, Fourth Edition.

https://doi.org/10.4324/9780203 427521

Wibowo, M. . (2015). Perspektif Konseling Multikultural dalam Masyarakat Indonesia. In Paper presented at Seminar Nasional Perspektif Konseling Berbudaya Multikultural. Semarang, Jawa Tengah.

Williams, M \& Schaps, E. (1999). Character Education: The foundation for teacher education. Washington DC: Character Education Partnership. (online). (https://searchworks.stanford.ed u/view/4495248).

Wing Sue, D., \& Sue, D. (2008). Counseling the culturally diverse: Theory and practice (5th ed.). Hoboken, NJ, US: John Wiley \& Sons Inc.

Yuzarion, Y., Alfaiz, A., Kardo, R., \& Dianto, M. (2018). Supervision in counseling service based on psychological test result to student's learning satisfaction. Konselor, 7(2), 63. https://doi.org/10.24036/020187 210736-0-00

Zed, M. (2008). Metode Penelitian Kepustakaan. Jakarta: Yayasan Obor Indonesia.

Zubaidah. (2014). Telaah Pepatah Minangkabau dan Kontribusinya dalam Konseling. Universitas Negeri Malang. 